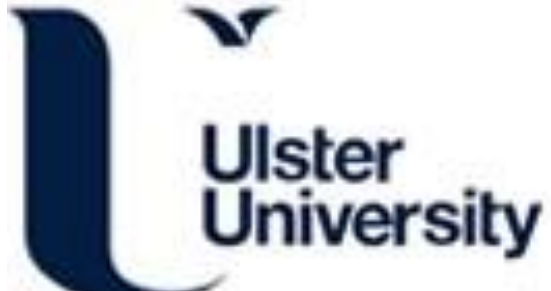

\section{Internalizing and externalizing disorders in childhood and adolescence: A latent transition analysis using ALSPAC data}

McElroy, E., Mark, S., \& Murphy, J. (2017). Internalizing and externalizing disorders in childhood and adolescence: A latent transition analysis using ALSPAC data. Comprehensive Psychiatry, 75, 75-84. https://doi.org/10.1016/j.comppsych.2017.03.003

Link to publication record in Ulster University Research Portal

\section{Published in:}

Comprehensive Psychiatry

Publication Status:

Published (in print/issue): 31/05/2017

DOI:

10.1016/j.comppsych.2017.03.003

\section{Document Version}

Author Accepted version

\section{General rights}

Copyright for the publications made accessible via Ulster University's Research Portal is retained by the author(s) and / or other copyright owners and it is a condition of accessing these publications that users recognise and abide by the legal requirements associated with these rights.

\section{Take down policy}

The Research Portal is Ulster University's institutional repository that provides access to Ulster's research outputs. Every effort has been made to ensure that content in the Research Portal does not infringe any person's rights, or applicable UK laws. If you discover content in the Research Portal that you believe breaches copyright or violates any law, please contact pure-support@ulster.ac.uk. 


\section{Accepted Manuscript}

Internalizing and externalizing disorders in childhood and adolescence: A latent transition analysis using ALSPAC data

Eoin McElroy, Mark Shevlin, Jamie Murphy

PII:

S0010-440X(16)30715-5

DOI: doi: 10.1016/j.comppsych.2017.03.003

Reference: $\quad$ YCOMP 51823

To appear in: $\quad$ Comprehensive Psychiatry

Please cite this article as: McElroy Eoin, Shevlin Mark, Murphy Jamie, Internalizing and externalizing disorders in childhood and adolescence: A latent transition analysis using ALSPAC data, Comprehensive Psychiatry (2017), doi: 10.1016/j.comppsych.2017.03.003

This is a PDF file of an unedited manuscript that has been accepted for publication. As a service to our customers we are providing this early version of the manuscript. The manuscript will undergo copyediting, typesetting, and review of the resulting proof before it is published in its final form. Please note that during the production process errors may be discovered which could affect the content, and all legal disclaimers that apply to the journal pertain. 
Internalizing and externalizing disorders in childhood and adolescence: A latent transition analysis using ALSPAC data

Eoin McElroy ${ }^{1}$, Mark Shevlin ${ }^{1}$, Jamie Murphy ${ }^{1}$

${ }^{1}$ Ulster University

Corresponding Author: Eoin McElroy, School of Psychology and Psychology Research Institute, Ulster University, Magee campus, Londonderry, BT48 7JL, Northern Ireland, Tel: +44 (0)28 71375341, Email: mcelroy-e1 @email.ulster.ac.uk

Conflicts of interest: none. 


\begin{abstract}
Background: Research examining the association between internalizing and externalizing dimensions of psychopathology has relied heavily on variable-centred analytical techniques. Person-centred methodologies complement the variable-centred approach, and may help explain the medium-to-large correlations that exist between higher order dimensions of psychopathology. What little person-centred research exists has been cross-sectional and utilised adult samples. The present study sought to take a person-centred approach to the modelling of psychiatric comorbidity during a key developmental phase; middle childhood through adolescence.
\end{abstract}

Methods: Analysis was conducted on data from the Avon Longitudinal Study of Parents and Children (ALSPAC, N=9,282). Latent transition analysis (LTA) was conducted using eight DSM-IV disorders assessed at ages 7.5 and 14 years as measured indicators.

Results: At both time points, a four class solution provided the best fit, with classes labelled as i) normative, ii) primarily internalizing, iii) primarily externalizing, and iv) highrisk/multimorbid. There was considerable individual-level stability across time, with approximately $80 \%$ of children remaining in the same class at both time points. Those in the internalizing class at baseline were more likely to transition to a less severe class (i.e. the normative class).

Conclusions: Person-centred methodologies demonstrate that the association between internalizing and externalizing is accounted for by a sub-population at high risk for experiencing psychiatric comorbidity, and 'cross-class' disorders which link the internalizing and externalizing spectra. 


\section{Introduction}

Dimensional models of psychopathology have been proposed in to account for widespread comorbidity between putatively distinct psychiatric disorders. Such models, based on factor analytic studies, suggest that psychopathology is better conceptualised as a small number of broad dimensions, rather than a multitude of discrete disorders [1-6]. The two most widely studied dimensions are internalizing (comprised of mood and anxiety disorders) and externalizing (comprised of substance abuse and behavioural disorders). Although dimensional models of psychopathology have garnered considerable empirical support, they have been hindered by moderate-to-high correlations between the dimensions themselves $[1,7]$. This is problematic given that dimensional models were originally developed to explain rather than simplify the relationships between psychiatric disorders.

The majority of studies that have attempted to explain this association have taken a variable-centred approach. Put simply, the variable-centred approach seeks to describe the association between variables, and assumes that these associations operate in a consistent manner across the population [8]. As such, variable-centred methods are appropriate for research questions concerning the relative importance of predictor variables in explaining variation in criterion variables [8]. The main variable-centred explanation for this correlation has been a superordinate dimension, or 'p-factor', thought to reflect a liability to experience any and all forms of psychopathology [9-10]. This model, however, has been criticised for its clinical application, and on methodological grounds [11-13]. Furthermore, an accepted interpretation of this factor has so far proven elusive, with $p$ plausibly reflecting shared aetiological agents (both genetic and environmental), or local level direct and indirect associations between disorders over time [9-10, 14-15] 
Relatively few studies of higher-order dimensions of psychopathology have taken a person-centred approach. The person-centred approach differs to the variable-centred approach in that it does not assume homogeneity within the entire population with regards to the influence of the predictor variables on outcomes [8]. Instead, person-centred methods identify homogeneous subgroups or classes of individuals within the overall population who share specific characteristics and associations between variables [8,16-17]. In simple terms, person-centred methodologies may complement variable-centred techniques by describing typical patterns of comorbidity within a given population [17-20]. This may help generate hypotheses as to the mechanisms that underpin this phenomenon.

Two separate studies have used person-centred methodologies to model psychiatric comorbidity using national epidemiological data $[18,19]$. In both cases, LCA identified best fitting solutions that consisted of five classes; (i) a normative class with a low probability of endorsing any disorder, (ii) an internalizing-fear class with a high probability of endorsing phobias, (iii) an internalizing -distress class with a high probability of endorsing mood and anxiety disorders (iv) an externalizing class, and (v) a multimorbid with a high probability of endorsing any disorder. Both studies also identified what were referred to as 'cross-class disorders', i.e. disorders that had reasonably high probabilities of crossing the traditional internalizing-externalizing divide. It has been suggested that the presence of these 'multimorbid' classes and 'cross-class disorders' may explain the overlap between internalizing and externalizing identified in previous studies [16, 17].

Spinhoven et al. [20] were the first to examine changes in these latent psychopathology classes over time. Taking data from a community cohort of adults $(n=2,566)$, they used latent transition analysis to examine individual-level changes between 
classes over time. They found that the likelihood of remaining in a particular comorbidity class was greater than making the transition to a class of lesser severity. This study focussed solely on the internalizing spectrum of disorders, meaning potential transitions between internalizing, externalizing and multimorbid classes remain unexplored.

The present study aims expand upon previous person-centred studies of higher-order dimensions of psychopathology by addressing a number of issues. First, previous studies have utilised lifetime diagnosis data from adult samples. To our knowledge, no personcentred studies have examined the structure of common mental disorders during childhood/adolescence. This developmental period involves many important biological (i.e. puberty) and socio-environmental (e.g. moving from primary to secondary education) changes, and has been identified as key window for the onset of many common psychiatric disorders [21]. Furthermore, the development of comorbid psychiatric disorders is reported to increase with age [21]. As such, person-centred studies utilising late childhood/adolescent samples may offer key insights into the early-stage structure of psychiatric comorbidity and subsequent developmental trajectories.

Second, and perhaps most importantly, to date only one person-centred study has examined the structure of psychopathology in a longitudinal context [20], however this study included internalizing disorders only. Therefore, the stability of internalizing, externalizing and multimorbid classes of psychopathology has yet to be examined. By examining individual-level transitions between internalizing, externalizing and multimorbid classes over time, we may gain a clearer picture of how these classes develop over time, and as such gain insight into the processes that underlie cross-spectrum comorbidity. 
Specifically, this study has two main aims; (i) to examine the latent class structure of common psychiatric disorders in a sample of children and adolescents, and (ii) to examine the person-level stability of these classes between childhood and adolescence. Latent class analysis (LCA) was employed to achieve the first aim, and latent transition analysis (LTA) was used to address the second aim of this study. Based on past research [18,19], it was predicted that a coherent class solution would emerge at ages 7.5 and 14 years and that this solution would reflect the following pattern; i) a normative class, ii) a class reflecting a high probability of endorsing internalizing disorders; iii) a class reflecting a high probability of endorsing externalizing disorders, and iv) a class reflecting a high probability of endorsing both internalizing and externalizing disorders (referred to as 'multimorbid'). Second, it was predicted that, while the majority of individuals would remain in the same class across time (i.e. stable), transitions across the identified classes would be relatively common. No a priori hypotheses regarding the direction of these transitions were specified.

\section{Method}

\subsection{Sample}

The current study utilised data from 4,525 mother-child pairs from the Avon Longitudinal Study of Parents and Children [22-23]. The ALSPAC is a prospective cohort study of children born in the English county of Avon between April $1^{\text {st }} 1991$ and December $31^{\text {st }} 1992$ $(\mathrm{N}=14,062)$. The sample is broadly representative of the overall population of children in the UK [22-23]. The ALSPAC was conducted to examine how genetic and environmental factors combine to influence health and development. The ALSPAC involved a diverse range of follow-ups, with 68 data collection points between birth and 18 years [22-23]. Data were collected using self-report postal questionnaires (completed by the study mothers and 
mother's partners) and yearly clinics for the study children from the age of 7 years [22-23]. Please note that the study website contains details of all the data that is available through a fully searchable data dictionary (http://www.bris.ac.uk/alspac/researchers/data-access/datadictionary/). Ethical approval for the study was obtained from the ALSPAC Ethics and Law Committee and the Local Research Ethics Committees. Further detailed descriptions of the ALSPAC can be found elsewhere [22-23].

\subsection{Measures}

Psychopathology was measured using the Development and Wellbeing Assessment (DAWBA) [24]. The DAWBA is a structured clinical interview designed to diagnose psychiatric disorders in 5-16 year olds based on ICD-10 and DSM-IV criteria. It is divided into 14 sections based on symptom profiles [24]. It contains questions regarding the frequency, severity, longevity and the impact of symptoms. It also contains open ended questions for clinical review [24]. Research indicates that the DAWBA is both a valid and reliable measure of psychopathology in clinical and general population contexts [24-26]. Parent-report, postal questionnaire versions of the DAWBA were administered when the study children were aged approximately $7.5,10.5$, and 14 years. Parents were asked to consider the DAWBA questions within a time frame of the past month. The following disorders were included in the present analysis; specific phobia (SPP), social phobia (SOP), generalised anxiety (GAD), major depression (DEP), post-traumatic stress (PTSD), attention/activity problems (ADHD), oppositional/defiant behaviour (ODD), and conduct problems (CD). Official DAWBA diagnoses based on clinical review were only available at one time point ( 7 years). For the present analysis, two time points were used; 7.5 and 14 years. These two points were chosen to allow adequate time for the development of psychiatric sequelae. As there were no clinical diagnoses available at the 14 year time point, 
the following comprehensive and conservative recoding strategy was adopted using available information from the 7.5 and 14 year time points;

For SOP, SPP, PTSD, GAD, DEP, and ATT, children were coded with a 1 if their parents reported that the child suffered both distress and impaired functionality as a result of a particular disorder. Those who did not experience both distress and impaired functionality were coded with a 0 (Fig 1.). For ODD, teacher complaint was used in place of distress, as distress does not reflect ICD-10/DSM-IV criteria for ODD (Fig 2.).

The DAWBA measure of conduct disorder differs significantly from the other symptom profiles, as distress and impaired functionality do not reflect ICD-10 and DSM-IV criteria for conduct disorder. Based on ALSPAC codebook guidelines, a binary variable named 'any frequent/definite conduct problems' was computed at the two assessment waves. For this variable, children were coded with a 1 if their parents reported that they definitely/ frequently told lies for personal benefit, started fights, bullied/threatened others, stayed out later than allowed, stole, ran away from home or played truant. All other children were coded as 0 . The above recoding strategies were applied to the eight symptom profiles at the two assessment waves. This recoding process resulted in 8 binary quasi-diagnostic variables $(1=$ present, $0=$ absent) at ages 7 and 13.5 years.

\subsection{Analytic strategy}

LTA is a longitudinal modelling technique used to examine whether individuals transition between latent classes over time. LTA consists of two components; a measurement model and an autoregressive model [27-28]. In LTA, the measurement model (i.e. LCA) describes the structure of the latent classes at the various time points [27-28]. The autoregressive model 
(i.e. Markov model) examines individual-level transitions between these classes over time [27-28]. For a much more detailed description of LTA and its applications in social and behavioural sciences see Nylund [27]. LTA was conducted in the following steps, as suggested by Nylund [27];

\section{Step 1: Determine the best measurement model}

To determine the best measurement model, a series of LCAs were specified and tested separately at the two time points using the eight binary disorder variables as observed indicators. Solutions consisting of $1-6$ latent classes were tested. Models were compared using a range of common fit statistics. The Akaike Information Criterion (AIC) [29], the Bayesian Information Criterion (BIC) [30], and the sample size- adjusted Bayesian Information Criterion (ssaBIC) [31] were used to compare model fit, with lower values indicative of better fit. The Lo-Mendel-Rubin likelihood ratio test (LMR-LRT) is used to compare a solution with $k$ number of classes with a solution with $k$-1 classes [32]. A nonsignificant $p$ value indicates that the model with $k$-1 classes provides a better fit [32]. Model fit was also assessed using the entropy criterion [33]. This statistic determines how accurately individuals were assigned to their classes based on the posterior probabilities [33]. Entropy values range from $0-1$, with higher values reflecting more accurate classification [33]. To ensure that the models converged on global rather than local solutions, 100 random sets of starting values and 10 final stage optimizations were used. 


\section{Step 2: Test for measurement invariance across time}

By examining measurement invariance, it is possible to determine whether a measurement model remains consistent over time (i.e. does the class solution at time1 have the same structure/meaning as the class solution at time 2). In LTA, measurement invariance is investigated by constraining conditional item probabilities to be equal across time. There are three levels of measurement invariance; full measurement invariance (i.e. all conditional item probabilities held equal across time), full-measurement non-invariance (i.e. all conditional item probabilities freely estimated across time), and partial measurement invariance (i.e. some conditional items held equal across time estimated across time, others freely estimated). In LTA, full-measurement invariance is preferable as it indicates the measurement model has the same meaning across time. This allows for a straightforward interpretation of the transition probabilities [27]. Measurement invariance was investigated by estimating competing models with different levels of constraint (full, full-non, and partial) and comparing them using the Log Likelihood Ratio Test (LRT). The LRT is a $\chi^{2}$ difference test based on the log likelihood values of the models and takes into account the scaling correction factors obtained when using the MLR estimator [34].

\section{Step 3: Specify latent transition model without covariates}

In this step, the LTA model is specified without covariates, producing a matrix of latent transition probabilities.

\section{Step 4: Specify latent transition model including covariates}

This optional step involves the inclusion of either observed or latent covariates in the model. Including covariates in a model results in changes to the estimation of the LTA model parameters, e.g. class size, transition probabilities $[27,35]$. As part of step 4 , it is possible to 
further examine heterogeneity in development by specifying a second-order latent moverstayer variable. A mover-stayer model classifies individuals as 'movers' (i.e. those who transition from one class to a different class over time) or 'stayers' (i.e. those who remain in the same class across time) [27-28]. Mover-stayer models more accurately describe transitions between classes, as transition probabilities are estimated for 'movers' only [2728].

\section{Results}

Step 0: Descriptive statistics

Table 1 shows the frequencies and relative percentages of the disorders at the different time points. GAD was the most common disorder, followed by DEP. The prevalence rates were lowest for PTSD, SOP and ODD. Z scores were used to examine whether there were significant increases/decreases in the prevalence rates over time.

There were significant increases in the prevalence of SOP, PTSD, GAD, and DEP between 7.5 and 14 years. There were no significant changes in the prevalence of SPP, ATT, ODD, and CD. Comorbidity was high; $41 \%$ of those who screened positive for any disorder at age 7.5 screened positive for two or more disorders. At age 13, this figure was $43 \%$.

\section{Step 1: Determine the best measurement model}

Table 2 presents the fit statistics for the different class solutions at ages 7.5 and 14 years BIC values, were lowest for the four class solutions. Entropy values were of a similar magnitude for the 4 and 5 class solutions. LMR-LRT values became non-significant when a 6 class solutions were specified at age 7.5 , suggesting a 5 class solution should be preferred. The 
LMR-LRT remained statistically significant even for the 6 class solution at age 14 , suggesting the optimal solution consisted of 6 or more classes. It remains debated whether the LMR-LRT or BIC is more useful when it comes to determining the optimal number of classes in an LCA [36]. A number of simulation studies suggest that the BIC is highly effective at identifying the correct underlying class structure, while the LMR-LRT can occasionally extract too many classes when the sample size is large $(\mathrm{N}>1,000)$ [36-37]. Given that the sample size was relatively large in the present study, the BIC was considered a more reliable indicator of the optimal class solution.

When deciding on which LCA solution to retain, it is also important to consider theory and the interpretability of the class solutions [27]. In the present analysis, the 4 class solution was easy to interpret at both ages (with 4 classes broadly representing normative, internalizing, externalizing, and multimorbid). The 5 class solution was also relatively easy to interpret (it resembled the 4 class solution, but a predominantly internalizing class that was split into internalizing-fear and internalizing-distress classes). The class solutions of 6 or greater (age 14) began to diverge from the internalizing-externalizing framework, and became increasingly difficult to interpret. As such, based on the performance of the BIC, overall model parsimony, and the theoretical clarity of the conditional item probabilities (see Fig. 3 and Fig. 4), the four class solution was chosen as the best fitting measurement model.

At both time points, class $1\left(N_{\mathrm{T} 1}=128,1.5 \% ; N_{\mathrm{T} 2}=103,1.4 \%\right)$ was labelled as 'high risk/multimorbid' and reflected a high probability of screening positive for either internalizing or externalizing disorders. Participants in class $2\left(N_{\mathrm{T} 1}=6,586,79.9 \% ; N_{\mathrm{T} 2}=\right.$ $5,702,80.2 \%$ ) had low probabilities of endorsing any internalizing or externalizing disorder. 
As such, this class was labelled as 'low endorsement/normative'. Class $3\left(N_{\mathrm{T} 1}=205,2.5 \%\right.$; $N_{\mathrm{T} 2}=312,4.4 \%$ ) was characterised by a high probability of endorsing an externalizing disorder and relatively low probability of endorsing internalizing disorders. This class was labelled 'externalizing'. Individuals in class $4\left(N_{\mathrm{T} 1}=1,324,16.1 \% ; N_{\mathrm{T} 2}=989,13.9 \%\right)$ had high probabilities of endorsing internalizing disorders, and a low probability of endorsing externalizing disorders, with the exception of ADHD which had a probability similar to the phobic disorders and PTSD. As such this class was named 'internalizing'.

\section{Step 2: Test for measurement invariance across time}

Table 3 presents fit statistics for the best fitting structural model (i.e. the 4 class solution), with two levels of constraints across time; (i) full measurement non-invariance (i.e. conditional item probabilities freely estimated across time), (ii) full measurement invariance (i.e. conditional item probabilities constrained to be equal at both time points). Measurement invariance was investigated by comparing the models using the Log Likelihood Ratio Test (LRT). The LRT indicated that there was a significant difference in model fit when the measurement constraints were added $\left(\Delta \chi^{2}=167.5, \mathrm{df}=32, \mathrm{p}<0.05\right)$.

An inspection of the BIC and sample size adjusted BIC suggested that the constrained model fit the data better than the unconstrained model. As such, full measurement invariance was assumed and used in subsequent steps of analysis. 
The latent transition probabilities are shown in Table 4. Overall, stability was the rule rather than the exception, with stability estimates ranging from 0.44 (multimorbid) and 0.88 (normative). Those in the 'high risk/multimorbid' class were more likely to transition to the internalizing group $(0.3)$ than either the predominantly externalizing $(0.12)$ or normative (0.14) classes. Those who were in the internalizing class at baseline were most likely to transition to the normative class $(0.34)$. Very few transitioned from the internalizing class to the multimorbid $(0.03)$ or externalizing $(0.02)$ classes.

A small proportion of the normative class made a transition to the internalizing class (0.09), with little probability of transitioning to the multimorbid (0.01), and externalizing classes (0.03). Finally, those who were in the externalizing class were more likely to transition to the multimorbid (0.12) or internalizing (0.20) classes, rather than the normative class $(6 \%)$.

\section{Step 4: Inclusion of latent mover-stayer covariate}

A latent mover-stayer variable was also specified and the mover-stayer patterns are displayed in Table 5. The majority of the sample were classified as stayers $(80.5 \%)$. With regards to movers, a number of interesting patterns emerged.

Moving from the normative class to the internalizing class, and vice versa, was relatively common. Moving from the externalizing class to the internalizing class was relatively common, however, the reverse pattern was relatively rare. Movers who were in the high risk/multimorbid class at baseline were most likely to move to the internalizing class at follow-up. 


\section{Discussion}

The present study aimed to take a person-centred approach to the modelling of psychiatric disorders in a cohort of children assessed in childhood and again in early-to-mid adolescence. LCA was used to examine the latent structure of eight common psychiatric disorders at two time points; 7.5 and 14 years. LTA was used to explore individual-level transitions between the identified classes across time. Furthermore, a latent mover-stayer variable was added to the model to gain a more detailed look at the individual-level transitions.

A four class structure was judged to provide the best approximation of the data at both time points. The largest class reflected low probabilities of endorsing any form of psychiatric disorder, and as such was named 'low endorsement/normative'. Two separate intermediate classes emerged reflecting high probabilities of endorsing predominantly internalizing and externalizing psychopathology. Finally, the smallest class reflected high risk for both internalizing and externalizing, and was labelled 'high risk/multimorbid'. A five class solution, in which the internalizing class split into separate 'fear' and 'distress' classes provided similar fit, but was rejected due to parsimony and the performance of the BIC. These class solutions suggest that individuals within the general population differ not only in overall psychopathological severity (i.e. a quantitative difference), but also partition into subpopulations who experience similar patterns of comorbidity (i.e. a qualitative difference).

Before examining the individual-level transitions between these classes, it was important to confirm that the preferred class solution was appropriate at both assessment waves, given the myriad of biological (e.g. puberty) and social (e.g. entering secondary school) changes that take place between childhood and adolescence [21]. Full measurement invariance was supported, suggesting that, at least from a structural point of view, psychiatric 
disorders were distributed in a similar manner from childhood through to mid adolescence, and such distributions were similar to those observed in adult populations [18-20].

The classes identified at both time points were extremely similar, both in terms of structure and counts, to solutions identified in previous person-centred studies [18-20]. Furthermore, the classes identified were in line with higher-order dimensions that have been reported in variable-centred studies [1-7]. Overall, these findings add further support to two explanations for the overlap of internalizing and externalizing dimensions, at least in statistical terms [18-19]. First, it appears that a sub-population exists within the general population which is characterized by a high likelihood of experiencing internalizing and externalizing disorders simultaneously. Second, there appears to be a number of 'cross-class' disorders, which fail to rest neatly within a particular psychopathological dimension. For example, in the predominantly internalizing class found in the present study, the conditional item probability for ADHD was of a similar magnitude to SPP, SOP, and PTSD. In factor analytic terms, 'cross-class' disorders may be considered as items that have crossloadings on multiple factors. As such, in purely mathematical/statistical terms, person-centred methodologies may be more effective at isolating the nuanced patterns of comorbidity that give rise to the association between internalizing and externalizing dimensions.

Unpacking the meaning behind these 'multimorbid' populations and 'cross-class disorders' is more challenging. Ultimately, two opposing schools of thought emerge, both of which appear frequently in the comorbidity literature; shared aetiology and causal interaction. In terms of shared aetiology, twin studies suggest that the associations between internalizing and externalizing domains can be explained by genetic and shared environmental factors [38]. As such, it is conceivable that the multimorbid population is reflective of children who 
have been exposed to the greatest risk for any and all psychopathology $[9,10]$. This idea is supported by the fact that, in both the present and past studies $[18,19]$, those in the multimorbid classes had the highest overall probabilities of endorsing both internalizing and externalizing disorders.

Alternatively it is possible that comorbidity arises due to direct and indirect casual associations. For example, it is possible that those who demonstrate externalizing behaviours in childhood (e.g. temper outbursts, poor attention, tendency towards violence) may experience negative outcomes in many different social situations (e.g. angry reactions from parents and teachers, social exclusion by peers, poor performance in school). These outcomes may in turn lead to general emotional distress (e.g. feelings of low mood, frustration, anxiety etc.). Such a pattern has been widely discussed in the literature and has been referred to as the 'failure model' [39-42]. The between-class transitions observed in the present study could be interpreted as being supportive of this model. Although the classes were generally quite stable over time, a notable pattern of transition emerged. Those who were in the internalizing class at baseline were proportionately more likely to make a transition to a less severe class (i.e. the normative class) than those who were in the externalizing class. This suggests that externalizing psychopathology at baseline may place an individual at greater risk of developing cross-domain comorbidity, compared with internalizing psychopathology. Furthermore, it appears that those who demonstrate externalizing behaviour in early childhood have a moderate chance of progressing to exclusively internalizing behaviour in adolescence, but the reverse is not the case. Such an interpretation is in line with the network approach to psychopathology, an increasingly popular alternative to dimensional models [1415]. Paying particular attention to ADHD, however, it is worth noting that twin studies have also attributed the overlap between ADHD and internalizing problems to shared genetic and 
environmental factors [43]. It may be difficult, to determine which, if either, school of thought is correct given experimental studies are not an option [44]. Indeed, there is nothing to suggest that both approaches are mutually exclusive [45-46]. Indeed future research could incorporate person centred methods in an attempt to determine to what extent psychiatric comorbidity is the product of shared aetiological agents and/or direct and indirect causal interactions. For example, research incorporating shared genetic and environmental risk factors could determine whether those in the multimorbid population have been exposed to the greatest amount of overall risk for psychopathology.

The findings of the present study should be considered in light of the following limitations. First, it must be noted that the measured indicators were not clinical diagnoses, as diagnoses were only available at a single time point. To address this, a comprehensive recoding strategy was adopted in which quasi-diagnostic variables were created. Second, disorders from other spectra (e.g. psychotic disorders) were unavailable at the assessment periods used in the present study. Third, it is worth noting that the disorders were based on DSM-IV criteria, and the criteria for a number of these disorders (e.g. PTSD) have undergone significant changes in the most recent edition of the DSM. Fourth, while the DAWBA is designed as a multi-informant measure of psychopathology, only parent completed reports were collected, meaning these reports could not be validated using teacher or self-reports. Fifth, while a latent mover-stayer variable was included in the model, the impact of observed covariates (e.g. gender) were not explored. Indeed, the inclusion of multiple covariates and distal outcomes can help describe heterogeneity in transitions as their inclusion alters the parameters of the model, and significant changes to the class structure following the inclusion of covariates can indicate problems with model specification [28, 47]. Finally, as previously discussed, the transition from childhood to adolescence is a period of rapid biological and 
social change. The present analysis ceased at mid-adolescence (approximately age 14). Further rapid development would be expected in subsequent years, therefore further research encompassing early, middle and late adolescence would be useful.

In conclusion, the present study sought to take a person-centred approach to the modelling of psychiatric comorbidity in a cohort of children assessed at age 7.5 and again at age 14 years. LCA identified a four class solution at both time points. The classes were labelled as follows; normative, internalizing, externalizing, and high-risk/multimorbid. Stability was the rule rather than the exception, however cross-dimension transitions were relatively common for those in the externalizing and multimorbid groups at baseline. The present study demonstrates that person-centred approaches may be a powerful tool in our attempts to determine to what extent psychiatric comorbidity is the product of shared aetiological agents and/or direct and indirect causal interactions. Person-centred methods may compliment variable-centred methods, as they are effective at describing nuanced patterns of psychiatric comorbidity.

\section{Acknowledgements}

We are extremely grateful to all the families who took part in this study, the midwives for their help in recruiting them, and the whole ALSPAC team, which includes interviewers, computer and laboratory technicians, clerical workers, research scientists, volunteers, managers, receptionists and nurses. The UK Medical Research Council and the Wellcome Trust (Grant ref: 092731) and the University of Bristol provide core support for ALSPAC. This publication is the work of the authors and the corresponding author will serve as guarantor for the contents of this paper. This research received no specific funding. 


\section{References}

1. Krueger, R. F., Caspi, A., Moffitt, T. E., \& Silva, P. A. (1998). The structure and stability of common mental disorders (DSM-III-R): A longitudinal-epidemiological study. Journal of Abnormal Psychology, 107(2), 216-227. doi: 10.1037/0021843X.107.2.216

2. Krueger, R. F., \& Markon, K. E. (2006). Reinterpreting comorbidity: A model-based approach to understanding and classifying psychopathology. Annual Review of Clinical Psychology, 2(1), 111-133. doi: 10.1146/annurev.clinpsy.2.022305.095213

3. Markon, K. E. (2010). Modeling psychopathology structure: A symptom-level analysis of Axis I and II disorders. Psychological Medicine, 40(2), 273-288. doi: $10.1017 / \mathrm{S} 0033291709990183$

4. Kotov, R., Chang, S. W., Fochtmann, L. J., Mojtabai, R., Carlson, G. A., Sedler, M. J., et al. (2011). Schizophrenia in the internalizing-externalizing framework: A third dimension? Schizophrenia Bulletin, 37(6), 1168-1178. doi: 10.1093/schbul/sbq024

5. Eaton, N. R., Krueger, R. F., \& Oltmanns, T. F. (2011). Aging and the structure and long-term stability of the internalizing spectrum of personality and psychopathology. Psychology and Aging, 26(4), 987-993. doi: 10.1037/a0024406

6. Markon, K. E., Chmielewski, M., \& Miller, C. J. (2011). The reliability and validity of discrete and continuous measures of psychopathology: A quantitative review. Psychological Bulletin, 137(5), 856-879. doi: 10.1037/a0023678

7. Krueger, R. F. (1999). The structure of common mental disorders. Archives of General Psychiatry, 56(10), 921-926. doi: 10.1001/archpsyc.56.10.921 
8. Laursen, B. P., \& Hoff, E. (2006). Person-centered and variable-centered approaches to longitudinal data. Merrill-Palmer Quarterly, 52(3), 377-389. doi: 10.1353/mpq.2006.0029

9. Caspi, A., Houts, R. M., Belsky, D. W., Goldman-Mellor, S. J., Harrington, H., Israel, S., et al. (2014). The p factor: One general psychopathology factor in the structure of psychiatric disorders?. Clinical Psychological Science, 2(2), 119-137. doi: $10.1177 / 2167702613497473$

10. Lahey, B. B., Hakes, J. K., Zald, D. H., Hariri, A. R., \& Rathouz, P. J. (2012). Is there a general factor of prevalent psychopathology during adulthood? Journal of Abnormal Psychology, 121(4), 971-977. doi: 10.1037/a0028355

11. Bonifay, W., Lane, S. P., \& Reise, S. P. (2016). Three concerns with applying a bifactor model as a structure of psychopathology. Clinical Psychological Science, doi:10.1177/2167702616657069.

12. Morgan, G. B., Hodge, K. J., Wells, K. E., \& Watkins, M. W. (2015). Are fit indices biased in favor of bi-factor models in cognitive ability research?: A comparison of fit in correlated factors, higher-order, and bi-factor models via monte carlo simulations. Journal of Intelligence, 3(1), 2-20. doi: 10.3390/jintelligence3010002

13. Murray, A. L., \& Johnson, W. (2013). The limitations of model fit in comparing the bi-factor versus higher-order models of human cognitive ability structure. Intelligence, 41(5), 407-422. doi: 10.1016/j.intell.2013.06.004

14. Borsboom, D., \& Cramer, A. (2013). Network analysis: An integrative approach to the structure of psychopathology. Annual Review of Clinical Psychology, 9(1), 91121. doi:10.1146/annurev-clinpsy-050212-185608 
15. Cramer, A., Waldorp, L., van der Maas, H., \& Borsboom, D. (2010). Comorbidity: A network perspective. Behavioral and Brain Sciences, 33(2-3), 137-150. doi:10.1017/s0140525x09991567

16. Magnusson, D. (2003). The person approach: Concepts, measurement models, and research strategy. New Directions for Child and Adolescent Development, 101, 3-23. doi: $10.1002 / \mathrm{cd} .79$

17. Bates, M. (2000). Integrating person-centered and variable-centered approaches in the study of developmental courses and transitions in alcohol use: Introduction to the special section. Alcoholism: Clinical and Experimental Research, 24(6), 878-881. doi: 10.1111/j.1530-0277.2000.tb02069.x

18. Vaidyanathan, U., Patrick, C. J., \& Iacono, W. G. (2011). Patterns of comorbidity among mental disorders: A person-centered approach. Comprehensive Psychiatry, 52(5), 527-535. doi: 10.1016/j.comppsych.2010.10.006

19. Olino, T. M., Klein, D. N., Farmer, R. F., Seeley, J. R., \& Lewinsohn, P. M. (2012). Examination of the structure of psychopathology using latent class analysis. Comprehensive Psychiatry, 53(4), 323-332. doi: 10.1016/j.comppsych.2011.05.008

20. Spinhoven, P., de Rooij, M., Heiser, W., Smit, J. H., \& Penninx, B. W. (2012). Personality and changes in comorbidity patterns among anxiety and depressive disorders. Journal of Abnormal Psychology, 121(4), 874. doi: 10.1037/a0028234

21. Kessler, R. C., Chiu, W. T., Demler, O., \& Walters, E. E. (2005). Prevalence, severity, and comorbidity of 12-month DSM-IV disorders in the National Comorbidity Survey Replication. Archives of General Psychiatry, 62(6), 617-627. doi: 10.1001/archpsyc.62.6.617

22. Boyd, A., Golding, J., Macleod, J., Lawlor, D. A., Fraser, A., Henderson, J., et al. (2012). Cohort profile: the 'children of the 90s' - the index offspring of the Avon 
Longitudinal Study of Parents and Children. International Journal of Epidemiology. doi: 10.1093/ije/dys064

23. Fraser, A., Macdonald-Wallis, C., Tilling, K., Boyd, A., Golding, J., Smith, G. D., et al. (2013). Cohort profile: The Avon Longitudinal Study of Parents and Children: ALSPAC mothers cohort. International Journal of Epidemiology, 42(1), 97-110. doi: 10.1093/ije/dys066

24. Goodman, R., Ford, T., Richards, H., Gatward, R., \& Meltzer, H. (2000). The Development and Well-Being Assessment: Description and initial validation of an integrated assessment of child and adolescent psychopathology. Journal of Child Psychology and Psychiatry, 41(5), 645-655

25. Brøndbo, P. H., Mathiassen, B., Martinussen, M., Heiervang, E., Eriksen, M., Moe, T. F., ... \& Kvernmo, S. (2011). The strengths and difficulties questionnaire as a screening instrument for norwegian child and adolescent mental health services, application of UK scoring algorithms. Child and Adolescent Psychiatry and Mental Health, 5(1), 1. doi: 10.1186/1753-2000-5-32

26. Mullick, M. S. I., \& Goodman, R. (2005). The prevalence of psychiatric disorders among 5-10 year olds in rural, urban and slum areas in Bangladesh. Social Psychiatry and Psychiatric Epidemiology, 40(8), 663-671. doi:10.1007/s00127-005-0939-5

27. Nylund, K. L. (2007). Latent transition analysis: Modeling extensions and an application to peer victimization. Doctoral Dissertation. University of California Los Angeles.

28. Nylund, K. L., Muthén, B., Nishina, A., Bellmore, A., \& Graham, S. (2006). Stability and instability of peer victimization during middle school: Using latent transition analysis with covariates, distal outcomes, and modeling extensions. mplus website. 
29. Akaike, H. (1987). Factor Analysis and AIC. Psychometrika, 52(3), 317-332. doi: 10.1007/BF02294359

30. Schwarz, G. (1978). Estimating the dimension of a model. The Annals of Statistics, $6(2), 461-464$.

31. Sclove, S. L. (1987). Application of model-selection criteria to some problems in multivariate analysis. Psychometrika, 52(3), 333-343. doi: 10.1007/BF02294360

32. Lo, Y., Mendell, N. R., \& Rubin., D. B. (2001). Testing the number of components in a normal mixture. Biometrika, 88(3), 767-778. doi: 10.1093/biomet/88.3.767

33. Celeux, G., \& Soromenho, G. (1996). An entropy criterion for assessing the number of clusters in a mixture model. Journal of Classification, 13(2), 195-212. doi: 10.1007/BF01246098

34. Satorra, A., \& Bentler, P. M. (2001). A scaled difference chi-square test statistic for moment structure analysis. Psychometrika, 66(4), 507-514. doi: 10.1007/BF02296192

35. Muthén, B., \& Asparouhov, T. (2011). LTA in Mplus: Transition probabilities influenced by covariates. Mplus Web Notes, (13).

36. Nylund, K. L., Asparouhov, T., \& Muthén, B. O. (2007). Deciding on the number of classes in latent class analysis and growth mixture modeling: A Monte Carlo simulation study. Structural Equation Modeling, 14(4), 535-569. doi: $10.1080 / 10705510701575396$

37. Tofighi, D., \& Enders, C. K. (2008). Identifying the correct number of classes in growth mixture models. Advances in Latent Variable Mixture Models, (Information Age Publishing, Inc), 317-341

38. Cosgrove, V. E., Rhee, S. H., Gelhorn, H. L., Boeldt, D., Corley, R. C., Ehringer, M. A., ... \& Hewitt, J. K. (2011). Structure and etiology of co-occurring internalizing and 
externalizing disorders in adolescents. Journal of Abnormal Child Psychology, 39(1), 109-123. doi: 10.1007/s10802-010-9444-8

39. Ostrander, R., \& Herman, K. C. (2006). Potential cognitive, parenting, and developmental mediators of the relationship between ADHD and depression. Journal of Consulting and Clinical Psychology, 74(1), 89-98. doi: 10.1037/0022006X.74.1.89

40. Masten, A. S., Roisman, G. I., Long, J. D., Burt, K. B., Obradović, J., Riley, J. R., et al. (2005). Developmental cascades: Linking academic achievement and externalizing and internalizing symptoms over 20 years. Developmental Psychology, 41(5), 733 746. doi: 10.1037/0012-1649.41.5.733

41. Capaldi, D. M. (1991). Co-occurrence of conduct problems and depressive symptoms in early adolescent boys: I. Familial factors and general adjustment at Grade 6. Development and Psychopathology, 3(3), 277-300. doi: 10.1017/S0954579400005319

42. Capaldi, D. M. (1992). Co-occurrence of conduct problems and depressive symptoms in early adolescent boys: II. A 2-year follow-up at Grade 8. Development and Psychopathology, 4(01), 125-144. doi: 10.1017/S0954579400005605

43. Chen, T. J., Ji, C. Y., Wang, S. S., Lichtenstein, P., Larsson, H., \& Chang, Z. (2015). Genetic and environmental influences on the relationship between ADHD symptoms and internalizing problems: A Chinese twin study. American Journal of Medical Genetics Part B: Neuropsychiatric Genetics. doi: 10.1002/ajmg.b.32411

44. Kessler, R., Avenevoli, S., McLaughlin, K., Green, J., Lakoma, M., \& Petukhova, M. et al. (2012). Lifetime co-morbidity of DSM-IV disorders in the US National Comorbidity Survey Replication Adolescent Supplement (NCS-A). Psychological Medicine, 42(09), 1997-2010. doi:10.1017/s0033291712000025 
45. Eaton, N. (2015). Latent variable and network models of comorbidity: Toward an empirically derived nosology. Social Psychiatry and Psychiatric Epidemiology, 50(6), 845-849. doi:10.1007/s00127-015-1012-7

46. Haslam, N. (2010). Symptom networks and psychiatric categories. Behavioral and Brain Sciences, 33(2-3), 158-159. doi:10.1017/s0140525x10000774

47. Perra, O. (2012). Latent Transition Analysis. Retrieved from restore.ac.uk: http://www.restore.ac.uk/latentvariablemodels/workshopfiles/Latent\%20Transition\%2 0Analysis_Oliver\%20Perra/Course\%20Presentation\%20and\%20Exercises/LTA_cour se_UU.pdf 
Figures and Tables

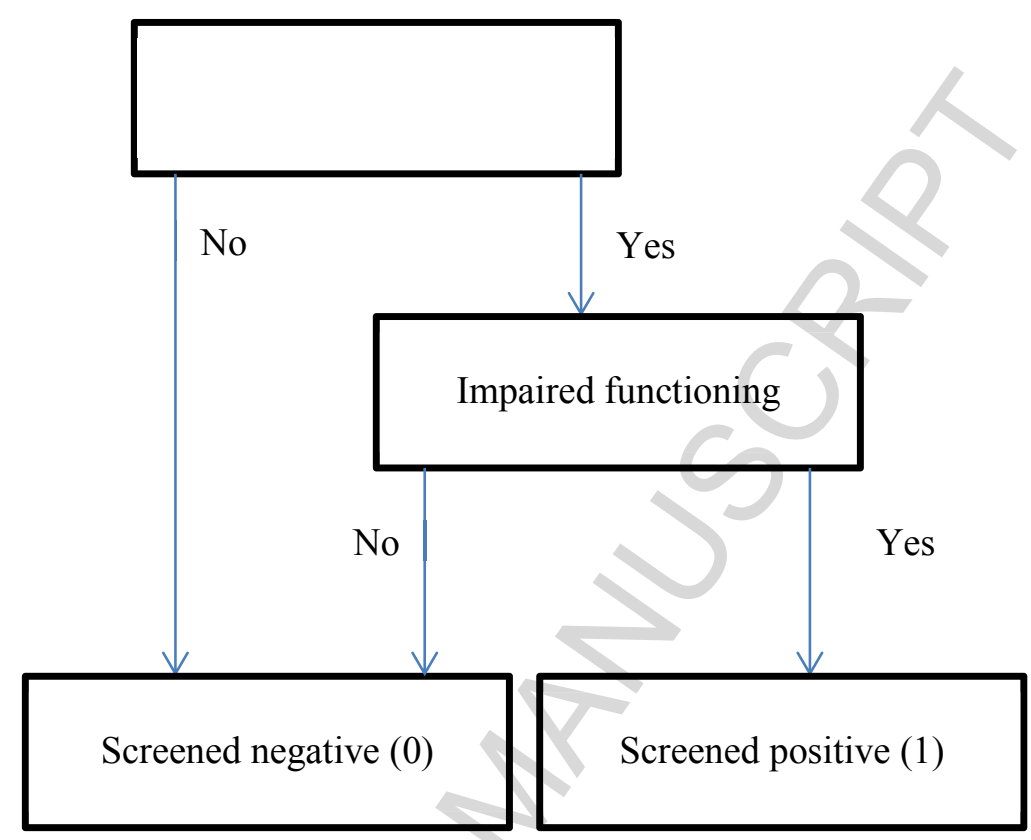

Fig 1. Graphical illustration of recoding process for SOP, SPP, PTSD, GAD, DEP, and ATT composite variables.

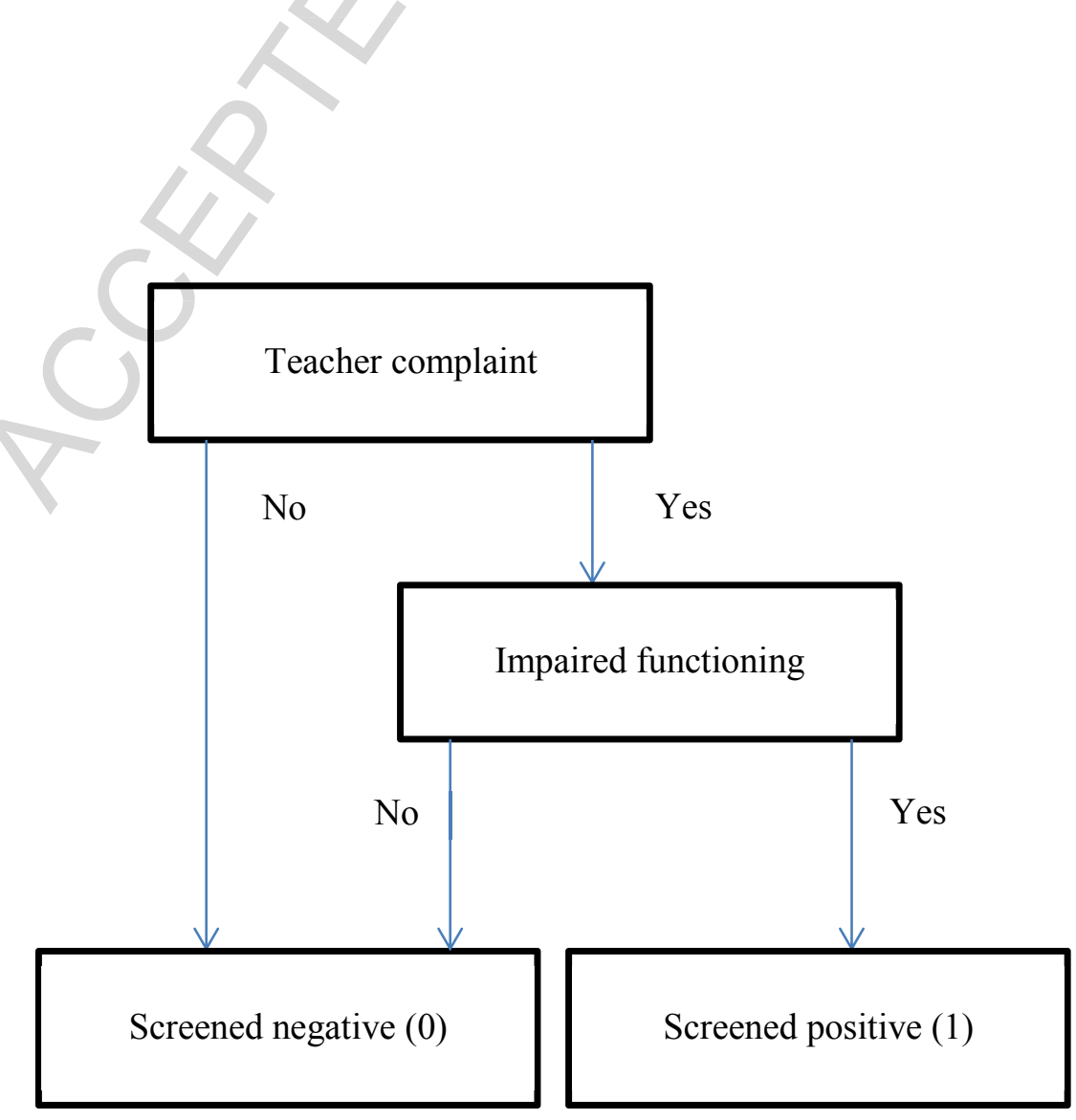

Fig 2. Graphical illustration of recoding process for ODD composite variables 


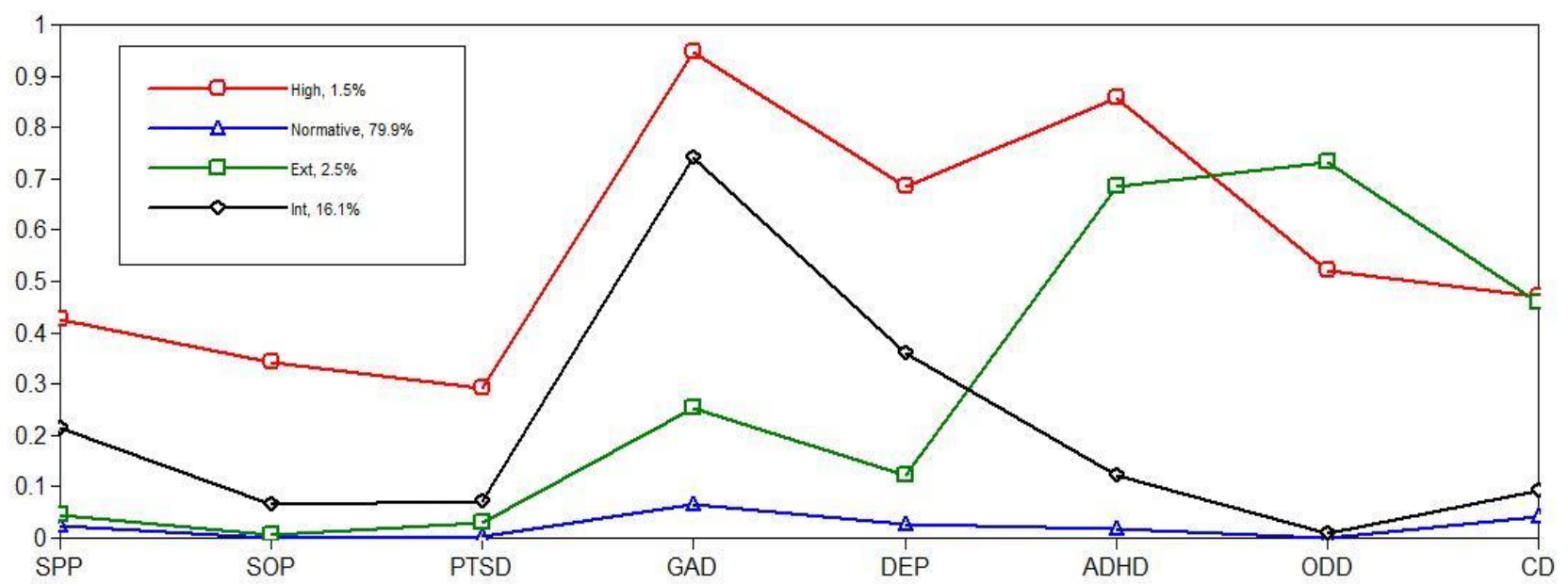

Fig. 3. Conditional item probabilities for 4 class solution at age 7.5 years. ; SPP= specific phobia; $\mathrm{SOP}=$ social phobia; $\mathrm{PTSD}=$ post-traumatic stress disorder; $\mathrm{GAD}=$ generalized anxiety; DEP = major depression; $\mathrm{ADHD}=$ attention/hyperactivity; $\mathrm{ODD}=$ oppositional/defiant behaviour; $\mathrm{CD}=$ conduct problems

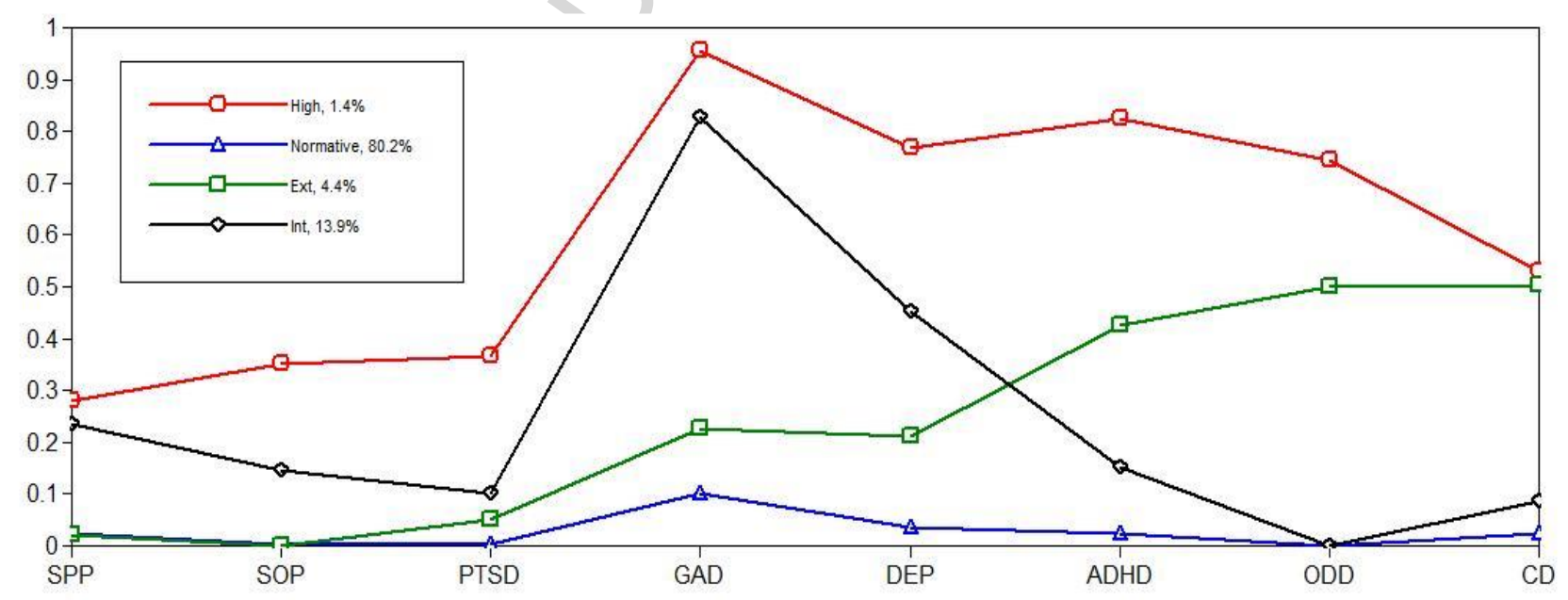

Fig. 4. Conditional item probabilities for 4 class solution at age 14 years. ; SPP= specific phobia; $\mathrm{SOP}=$ social phobia; $\mathrm{PTSD}=$ post-traumatic stress disorder; $\mathrm{GAD}=$ generalized anxiety; $\mathrm{DEP}=$ major depression; $\mathrm{ADHD}=$ attention/hyperactivity; $\mathrm{ODD}=$ oppositional/defiant behaviour; $\mathrm{CD}=$ conduct problems 
Table 1. Frequencies, relative percentages and $\mathrm{Z}$ scores of measured indicators by assessment period

\begin{tabular}{|c|c|c|c|c|c|}
\hline & & 7 years & 13.5 years & $Z$ & $p$ \\
\hline SPP & $\begin{array}{l}\text { Present } \\
\text { Absent } \\
\text { Total }\end{array}$ & $\begin{array}{l}450(6.5 \%) \\
6926 \\
7376\end{array}$ & $\begin{array}{l}401(5.6 \%) \\
6705 \\
7106\end{array}$ & 1.17 & .242 \\
\hline SOP & $\begin{array}{l}\text { Present } \\
\text { Absent } \\
\text { Total }\end{array}$ & $\begin{array}{l}136(1.6 \%) \\
8009 \\
8145\end{array}$ & $\begin{array}{l}200(2.8 \%) \\
6906 \\
7106\end{array}$ & & .000 \\
\hline PTSD & $\begin{array}{l}\text { Present } \\
\text { Absent } \\
\text { Total }\end{array}$ & $\begin{array}{l}153(1.8 \%) \\
7961 \\
8114\end{array}$ & $\begin{array}{l}173(2.4 \%) \\
6933 \\
7106\end{array}$ & -2.33 & .020 \\
\hline GAD & $\begin{array}{l}\text { Present } \\
\text { Absent } \\
\text { Total }\end{array}$ & $\begin{array}{l}1548(19 \%) \\
6563 \\
8111\end{array}$ & $\begin{array}{l}1557(21.9 \%) \\
5549 \\
7106\end{array}$ & -4.32 & .000 \\
\hline DEP & $\begin{array}{l}\text { Present } \\
\text { Absent } \\
\text { Total }\end{array}$ & $\begin{array}{l}742(9 \%) \\
7357 \\
8099\end{array}$ & $\begin{array}{l}795(11.2 \%) \\
6311 \\
7106\end{array}$ & -4.13 & .000 \\
\hline ADHD & $\begin{array}{l}\text { Present } \\
\text { Absent } \\
\text { Total }\end{array}$ & $\begin{array}{l}497(6 \% \\
7342 \\
7839\end{array}$ & $\begin{array}{l}497(7 \%) \\
6609 \\
7106\end{array}$ & -1.60 & 0.11 \\
\hline ODD & $\begin{array}{l}\text { Present } \\
\text { Absent } \\
\text { Total }\end{array}$ & $\begin{array}{l}220(2.7 \%) \\
7787 \\
8007\end{array}$ & $\begin{array}{l}233(3.2 \%) \\
6873 \\
7106\end{array}$ & -1.91 & .056 \\
\hline $\mathrm{CD}$ & $\begin{array}{l}\text { Present } \\
\text { Absent } \\
\text { Total }\end{array}$ & $\begin{array}{l}544(6.7 \%) \\
7650 \\
8194\end{array}$ & $\begin{array}{l}424(6.1 \%) \\
6486 \\
6910\end{array}$ & 0.25 & .802 \\
\hline
\end{tabular}

$Z=Z$ score; $\mathrm{p}=$ probability value of $\mathrm{Z}$ score; $\mathrm{SPP}=$ specific phobia; $\mathrm{SOP}=$ social phobia; $\mathrm{PTSD}=$ posttraumatic stress disorder; GAD = generalized anxiety; $\mathrm{DEP}=$ major depression; $\mathrm{ADHD}=$ attention/hyperactivity; $\mathrm{ODD}=$ oppositional/defiant behaviour; $\mathrm{CD}=$ conduct problems. 
Table 2. Fit statistics for disorder classes at age 7.5 and 14 years

\begin{tabular}{|c|c|c|c|c|c|c|c|}
\hline Class & $\log$ & $\begin{array}{r}\# \\
\text { par }\end{array}$ & AIC & $\mathrm{BIC}$ & ssaBIC & LRT (p) & Entropy \\
\hline \multicolumn{8}{|l|}{ Age } \\
\hline 7.5 & & & & & & & \\
\hline 1 & -14439.681 & 8 & 28895.362 & 28951.499 & 28926.076 & - & - \\
\hline 2 & -13227.812 & 17 & 26489.624 & 26608.915 & 26554.893 & $\begin{array}{r}2394.2 \\
(.000)\end{array}$ & 0.755 \\
\hline 3 & -13036.173 & 26 & 26124.347 & 26306.792 & 26224.169 & $\begin{array}{r}378.61 \\
(.000)\end{array}$ & 0.822 \\
\hline 4 & -12974.548 & 35 & 26019.097 & 26264.696 & 26153.473 & $\begin{array}{r}121.75 \\
(.000)\end{array}$ & 0.820 \\
\hline 5 & -12951.548 & 44 & 25991.096 & 26299.849 & 26160.025 & $\begin{array}{l}45.44 \\
(.002)\end{array}$ & 0.800 \\
\hline 6 & -12942.826 & 53 & 25991.652 & 26363.559 & 26195.135 & $\begin{array}{l}17.30 \\
(.506)\end{array}$ & 0.902 \\
\hline \multicolumn{8}{|l|}{ Age 14} \\
\hline 1 & -13914.225 & 8 & 27844.450 & 27899.399 & 27873.977 & - & - \\
\hline 2 & -12711.586 & 17 & 25457.172 & 25573.940 & 25519.918 & $\begin{array}{r}2375.5 \\
(.000)\end{array}$ & 0.751 \\
\hline 3 & -12515.135 & & 082.270 & 25260.856 & 25178.234 & $\begin{array}{r}388.04 \\
(.000)\end{array}$ & 0.823 \\
\hline 4 & -12435.888 & 35 & 24941.776 & 25182.180 & 25070.958 & $\begin{array}{r}156.53 \\
(.000)\end{array}$ & 0.829 \\
\hline 5 & -12398.793 & 44 & 24885.586 & 25187.808 & 25047.987 & $\begin{array}{r}73.272 \\
(.003)\end{array}$ & 0.830 \\
\hline 6 & -12383.446 & 53 & 24872.891 & 25236.932 & 25068.510 & $\begin{array}{r}30.315 \\
(.041)\end{array}$ & 0.843 \\
\hline
\end{tabular}


Table 3. Fit statistics investigating full and full-non measurement invariance

\begin{tabular}{lllllll}
\hline Class & Log & $\begin{array}{l}\# \\
\text { par }\end{array}$ & AIC & BIC & ssaBIC & $\begin{array}{l}\text { LRT X } X^{2} \\
(\Delta \mathrm{df}), \mathrm{p}\end{array}$ \\
\hline $\begin{array}{l}\text { Full non- } \\
\text { invariance }\end{array}$ & -25410.436 & 70 & 50960.873 & 51460.381 & 51237.933 & - \\
$\begin{array}{l}\text { Full } \\
\text { invariance }\end{array}$ & -25449.965 & 38 & 50975.929 & 51247.091 & 51126.333 & $\begin{array}{l}167.5(32), \\
\mathrm{p}<0.05 *\end{array}$ \\
\hline
\end{tabular}

* indicates fully invariant model fit significantly worse than fully non-invariant model 
Table 4. Latent transition probabilities from Age 7.5 to Age 14

\begin{tabular}{llcccc}
\hline $\begin{array}{l}\text { Age } 7.5 \\
\text { below }\end{array}$ & $\begin{array}{l}\text { Age 14 } \\
\text { across }\end{array}$ & 1. Multi & 2. INT & 3. Norm & 4. EXT \\
\hline & & & & & \\
1. Multi & 0.44 & 0.30 & 0.14 & 0.12 \\
2. INT & 0.03 & 0.61 & 0.34 & 0.02 \\
3. Norm & 0.01 & 0.09 & 0.88 & 0.03 \\
4. EXT & 0.12 & 0.20 & 0.06 & 0.62
\end{tabular}

EXT $=$ primarily externalizing class; INT $=$ primarily internalizing distress class; multi $=$ high endorsement/multimorbid class; Norm = low endorsement/normative class. 
Table 5. Count and relative percent of mover-stayer patterns

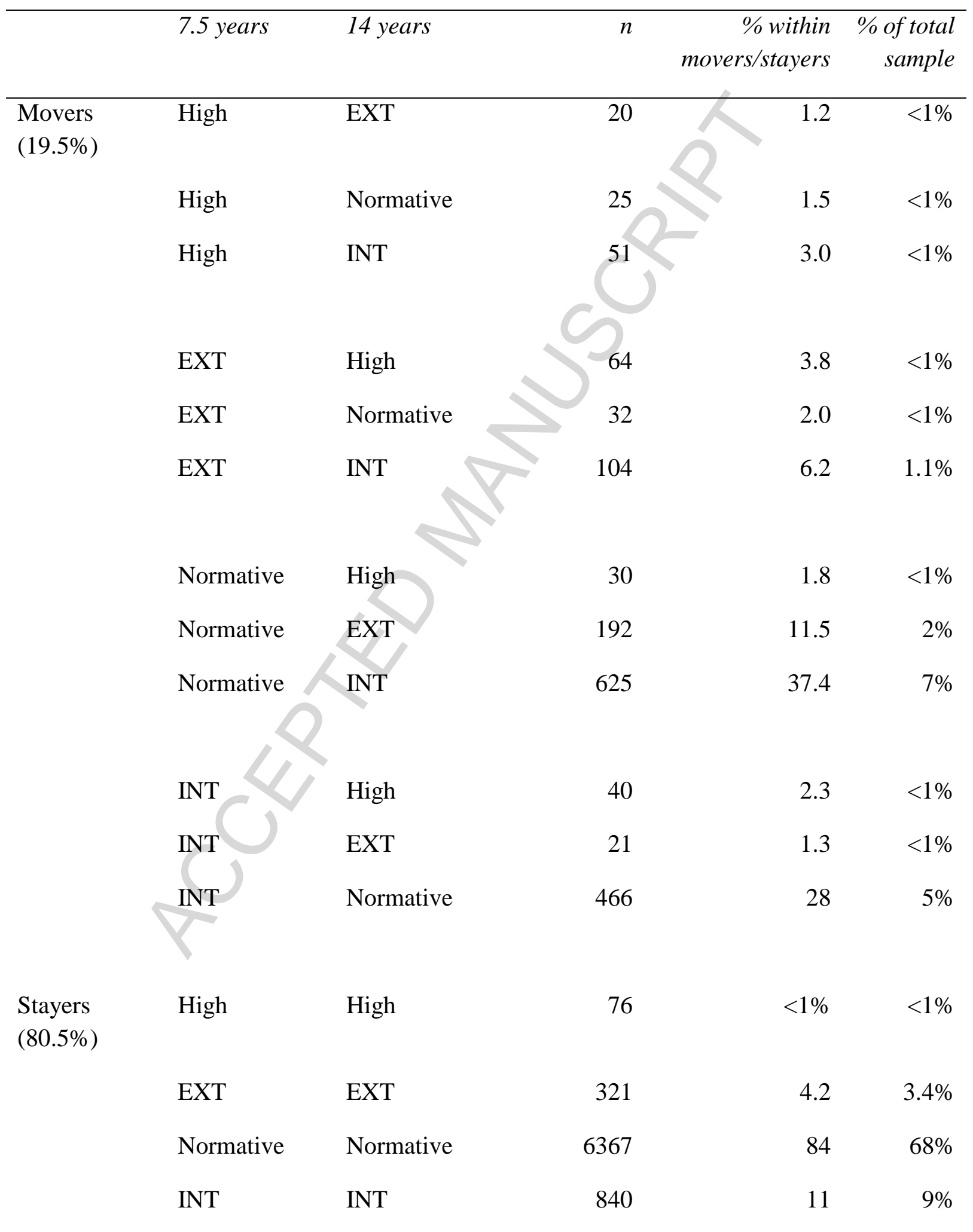

EXT $=$ primarily externalizing class; INT $=$ Primarily internalizing distress class , High $=$ high endorsement/multimorbid class; Low $=$ low endorsement/baseline class 